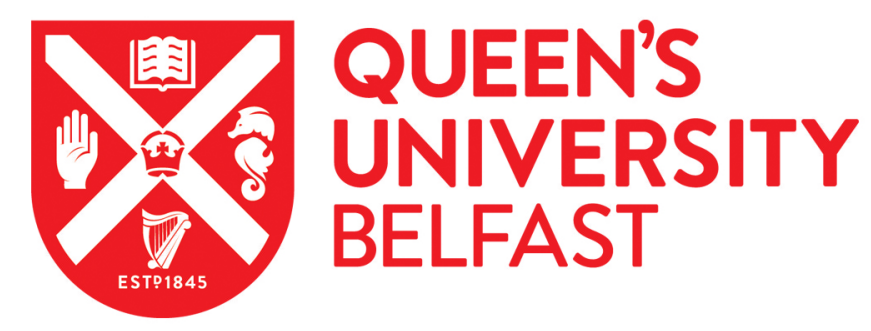

\title{
Stress and coping in parents of newly born twins
}

Kehoe, A., Dempster, M., McManus, J., \& Lewis, S. (2016). Stress and coping in parents of newly born twins. Journal of Psychosomatic Obstetrics and Gynecology, 37(3), 110-118.

https://doi.org/0.1080/0167482X.2016.1175427

Published in:

Journal of Psychosomatic Obstetrics and Gynecology

Document Version:

Peer reviewed version

Queen's University Belfast - Research Portal:

Link to publication record in Queen's University Belfast Research Portal

Publisher rights

Copyright 2016 Taylor and Francis

This is an Accepted Manuscript of an article published by Taylor \& Francis in Journal of Psychosomatic Obstetrics and Gynecology on 16 May 2016, available online: http://www.tandfonline.com/doi/full/10.1080/0167482X.2016.1175427

\section{General rights}

Copyright for the publications made accessible via the Queen's University Belfast Research Portal is retained by the author(s) and / or other copyright owners and it is a condition of accessing these publications that users recognise and abide by the legal requirements associated with these rights.

Take down policy

The Research Portal is Queen's institutional repository that provides access to Queen's research output. Every effort has been made to ensure that content in the Research Portal does not infringe any person's rights, or applicable UK laws. If you discover content in the Research Portal that you believe breaches copyright or violates any law, please contact openaccess@qub.ac.uk. 
Stress and Coping in Parents of Newly Born Twins

Running head: Stress and Coping in Parents

Authors: ${ }^{1}$ Anne Kehoe PhD, ${ }^{1}$ Martin Dempster PhD, ${ }^{2}$ Joanne McManus MD, ${ }^{3}$ Sheena Lewis $\mathrm{PhD}$

1School of Psychology, Queen’s University Belfast, David Keir Building, 18-30 Malone Road, Belfast BT9 5BP.

${ }^{2}$ Royal Jubilee Maternity Services, 274 Grosvenor Road, Belfast, BT12 6BA.

${ }^{3}$ Centre for Public Health, Queen's University, Room 0017, Ground Floor, Institute of Pathology, Grosvenor Road, Belfast,BT12 6BJ, Northern Ireland.

Key words: Infertility, Coping, Parents, Stress, Twins. 


\begin{abstract}
OBJECTIVE: Research indicates that parents of twins have poorer psychosocial outcomes than parents of singletons. Parents who have conceived using Assisted Reproductive Technology (ART) have been found to be at higher risk of negative psychosocial outcomes compared to parents who have conceived spontaneously. The current study aimed to model the factors associated with parenting stress of newly-born twins, using the Transactional Model of Stress.
\end{abstract}

METHODS: Data were collected using a cross-sectional survey design with participants identified from delivery records across Northern Ireland. Mothers and fathers $(n=104)$ of twins aged between 1 month and 12 months old returned a questionnaire pack containing the Parenting Stress Index, Impact on the Family Scale-Financial Burden, Coping Orientation to Problems Experienced - Brief Version, Multidimensional Scale of Perceived Social Support, General Health Questionnaire and a demographic questionnaire.

RESULTS: There were no differences on psychological outcomes between parents who had conceived via ART and those who conceived spontaneously. Regression analyses found that that social interaction and support is an important variable in terms of the psychological outcomes experienced by parents of twins.

CONCLUSION: Parents of newly-born twins regardless of the mode of conception should be considered an at risk group for parental distress. Support groups such as the Twins and Multiple Births Association could be important in providing that crucial social interaction and support that seems to be important in the emotional well-being of parents of twins. 


\section{Current knowledge on the subject}

- Parents of twins have poorer psychosocial outcomes than parents of singletons.

- Parents who have conceived using Assisted Reproductive Technology (ART) have poorer psychosocial outcomes than parents who have conceived spontaneously.

- However, the research in this area is contradictory as it confounds multiple births with ART.

\section{What this study adds}

- This study examines parenting stress among parents of newly-born twins to determine whether conception via assisted reproductive technology (ART) and other potential stressors were an important determinant of psychological outcomes.

- There are no differences on psychological outcomes between parents of twins who had conceived via ART and those who conceived spontaneously.

- Social interaction and support is an important determinant of psychological outcomes. 
Introduction

Stress has been found to have detrimental effects on the parent, such as low marital satisfaction [1] and post-natal depression [2]. The presence of high levels of parenting stress has also been shown to be associated with poor psychosocial outcomes for the child [3], such as child behavioural problems [4] and maternal neglect [5]. Clearly, the alleviation of parenting stress at an early stage in parenthood could have beneficial consequences for the entire family.

In addition to the high ante- and peri-natal risk profile of twin pregnancies (due to, for example, higher rates of prematurity and low birth weight [6]), they are also associated with many social, psychological and economic challenges [7]. Multiple births have a welldocumented negative impact on post-natal maternal emotional well-being [8,9]. Raising two children places huge demands on parents’ time which may result in sleep deprivation, exhaustion, little personal time, depression and financial difficulties [10,11]. Consequently, twins may have less time with their parents [12], which might help to explain the finding that mothers of twins were found to be less responsive, less involved and less likely to engage in elaborate interaction with their children compared to mothers of singletons [13]. It has been predicted that twins may be less likely to become securely attached to their mother and therefore are more at risk of psychological problems as they grow up [14].

The evidence relating parenting stress and conception via assisted reproductive technologies (ART) is more mixed. Many of the established risk factors for low mood after childbirth, including being young, single, of low socioeconomic status [15], are absent from or rare in ART populations, which could then lead to the expectation that postnatal mood disturbance would be unusual in this population. However research has reported that $17.1 \%$ of ART mothers of singletons had clinically significant depressive symptoms [16]. A systematic review examined the effects of ART on the psychological and social aspects of 
pregnancy, childbirth and infant parenthood [17]. The review concluded that there is consistent evidence that emotional well-being, marital satisfaction and parent-infant relationships in ART parents are similar to those who have conceived spontaneously [17]. However for ART parents, early parenting difficulties were found to be higher and post-natal self-confidence lower. They concluded that the body of evidence in this area is currently 'emergent' and that in ART pregnancy, parenthood may be idealized and this may hinder adjustment and the development of a confident parental identity [17].

It may be the case that the evidence about parents’ psychological outcomes after ART is mixed because of the confound between ART and twin births. ART is associated with increasing rates of twin pregnancies and births [18]. The Human Fertilization and Embryology Authority (HFEA) has identified multiple births as the biggest risk factor from In Vitro Fertilisation (IVF). In the UK, $23.6 \%$ of all births from IVF are twin or triplet births [19]. Infertility and subsequent treatment are emotionally and physically stressful and are linked with increased levels of anxiety and depression during treatment [20]. Yet, for infertile couples the prospect of twins may be viewed positively as a way of completing their family without further stressful, risky and expensive treatment [21].

The current research aims to examine the factors associated with parenting stress and to determine whether spontaneous conception is better than ART, in terms of psychological outcomes, among parents of newly-born twins.

For the current research the conceptualisation of parenting stress is based on the Transactional Model of Stress (TMS) [22]. The TMS has been used previously in conceptualising parenting stress $[23,24]$. TMS proposes that there is not a direct link between stressors (potentially stressful events) and stress outcomes (such as emotional distress), but that this relationship is moderated by the coping resources available to the individual. More specifically, TMS suggests that when a potential stressor arises the individual makes a 
primary appraisal to consider whether the potential stressor is threatening or not. During secondary appraisal the individual considers whether they have the resources to deal with the actual stressor and whether these resources can be brought to bear on the stressor in a beneficial way. Primary and secondary appraisal can happen simultaneously and these appraisals will be influenced by a range of factors such as previous experience with this type of stressor, the types of coping strategies commonly used by the person, and the availability of social support. These variables are considered moderators in the relationship between stressor and outcome. In the current research, we examine the relationship between commonly identified parenting stressors and stress outcomes (depression, sense of parenting competence and general mental well-being) and the extent to which this relationship is moderated by coping strategies and social support. We also consider conception via ART (or not) to be a potential stressor in this model (see Figure 1).

Previous research examining the differences between parents of twins conceived via ART and parents of twins conceived spontaneously, has presented mixed findings, suggesting that parents of twins conceived via ART experience greater levels of stress than parents who conceived naturally [23,25], or that there was no difference between these groups [26]. The current study aims to clarify the contradictions in this previous research by including an analysis of the relationship between other potential stressors (in addition to the type of conception) and moderators and the stress outcome.

The specific research questions to be addressed by the current study are: (1) What is the relationship between parenting-related stressors (including conception by ART or not) and psychological outcomes (depression, sense of parenting competence and general mental well-being) among new mothers and fathers of twins? (2) To what extent is the relationship between parenting-related stressors and psychological outcomes moderated by parents’ coping strategies and perceptions of support? 
Methods

Participants

Participants were 104 parents (73 mothers and 31 fathers) of twins (61 ART and 43 non-ART) between 1 and 12 months old. Parents were deemed eligible for participation if they were at least 18 years of age. Parents were identified from delivery records across Northern Ireland. A total of 355 packs were sent to parents identified. Each pack contained two questionnaires, one for the mother and one for the father. All information was sent to the mother, with a request to pass the second study pack to the father.

All participants consented to their data being used in the study and the study was approved by the National Health Service Research Ethics Committee Service.

Measures

The questionnaire booklets contained the following questionnaires:

Parenting Stress Index (PSI) [5]. The PSI contains 7 scales which provide information about the parent; 6 scales which provide information about the characteristics of the child and a life stress scale which asks about other major life events that have taken place in the parent's life during the past 12 months. The 7 scales that provide information about the parent (Parent Domain) are: sense of competence (parent’s perception of competence in parenting), social isolation (availability of social interaction for the parent), attachment (parent's motivation to fulfil the role of a parent), health (the impact of the parent's physical health in meeting the demands of parenting), role restriction (the impact of parenthood on the parent's personal freedom and other life roles), depression (the extent to which the parent's emotional availability to the child is impaired) and relationship with partner (emotional and physical support provided by partner). The 6 scales which provide information about the characteristics of the child (Child Domain) include 4 temperament-related characteristics of 
distractibility/hyperactivity, adaptability, demandingness and mood, and 2 scales related to the parent-child interaction: reinforces parent (the extent to which the parent-child interaction results in a positive affective response in parents) and acceptability (how closely the child meets the parent's expectations). Higher scores on the PSI represent higher levels of stress in the area covered by the subscale. The PSI has been tested extensively and support is provided for its reliability and validity [5,27]. It has been used in previous research to examine parenting stress among mothers of twins conceived spontaneously and via ART $[16,26]$. The depression and sense of competence scales from the PSI will be treated as outcome measures in the current study.

Impact on Family Scale - Financial Burden [28]. This 4-item scale assesses the appraisal of the financial concerns of parents. The 4 items are summed to compute a total financial burden score. The reliability and validity of the scale is supported [29].

Coping Orientation to Problems Experienced - Brief Version (Brief COPE) [30]. This 28 item questionnaire assesses 14 strategies for coping: self-distraction, active coping, denial, substance use, emotional support, instrumental support, behavioral disengagement, venting, positive reframing, planning, humour, acceptance, religion, and self-blame. This is a shortened version of the 60-item COPE [31]. Carver [30] provides evidence for the reliability and validity of the instrument. The Brief COPE has been used in previous research to examine coping with parenting stress [24]. A high score on each subscale indicates higher use of the respective coping strategy.

The Multidimensional Scale of Perceived Social Support (MSPSS) [32]. This 12-item measure comprises three facets: support from friends, family and significant others. Higher scores on each of the subscales indicate higher levels of perceived support. Evidence for validity and reliability is provided [32,33]. This measure has been used in previous research examining stress and coping among mothers of twins [23]. 
General Health Questionnaire (GHQ-12) [34]. The GHQ-12 provides a measure of general mental well-being. The GHQ-12 has been validated against longer versions of the GHQ [35]. The GHQ has been used in previous research to examine outcomes of parenting stress among mothers of twins conceived spontaneously and via ART [16,26,36]. There is sound psychometric evidence for the scale [37]. Higher GHQ scores indicate poorer mental well-being. The GHQ-12 will be used as an outcome measure in this study.

Demographic Questionnaire. This included questions on the age range, employment status, length of leave from employment after the birth of twins, education level, relationship status, duration of relationship, length of time trying to conceive before the birth of the twins, whether infertility treatments were used, type of infertility treatment used, number of infertility treatments, parity, age of twins, gestational age of twins, birth-weight of twins, any birth complications for the children or mother, any current or recent counselling. Analysis

The main focus of the analysis was to examine whether the demographic variables, potential stressors (PSI subscales, financial burden and ART or not) and potential moderators (coping and social support) were related to psychological outcomes (PSI subscales of sense of competence and depression and the GHQ) using multiple regression. Some preliminary work was conducted to reduce the number of variables to be included in this analysis:

1. The coping variables were reduced using principal components analysis, with direct oblimin rotation. Two components were extracted on the basis of the scree plot and these were labelled as approach coping and avoidant coping (see Table 1 for a summary of the component loadings). The two components were calculated using standardised scores, resulting in scales with a mean of 0 and a standard deviation of 1 . Higher scores on each scale mean that this type of coping was used more often. 
2. Each outcome variable was regressed separately on each interaction between the potential moderators (coping and social support) and potential stressors (PSI subscales, financial burden and ART or not). Only those interaction terms that made a statistically significant contribution $(\mathrm{p}<.05)$ to an outcome variable in the presence of their main effects were retained.

3. Each outcome variable was regressed on each block of independent variables (block 1: demographic variables; block 2: potential stressors; block 3: the approach and avoidant coping factors; and block 4: the MPSS scales). Variables were retained if $\mathrm{p}<$ .10. This more liberal significance level was used to guard against the risk of pertinent variables being lost to the final analyses.

4. The final analyses involved conducting a linear regression for each outcome variable separately. The independent variables in the regression analyses were the potential stressors, coping strategies, social support variables, and interaction terms retained after the preliminary analyses outlined above. The demographic variables did not make a contribution to any of the outcome variables based on the criteria listed above for the preliminary analyses and so were not included in the final analyses.

Results

This was the second pregnancy for the majority of participants. Among the participants who had used infertility treatment, they had 4 treatments (on average). Other results from the demographic questionnaire are presented in Table 2. Data are available on the age of mothers of twins born in 2014 in the population [38]. A comparison between this population data and our sample data indicates that there is no statistically significant difference in maternal age $\left(\chi^{2}=9.54, \mathrm{p}=.09\right)$. 
Descriptive data for all self-report measures are included in Table 3. Participants scored around the threshold (on average) for clinical 'caseness' on the GHQ [35]. However, they were lower than the threshold for probable depression and sense of parenting competence on the PSI Depression and PSI Competence scales, scoring around the norm mean value in both cases.

In the final regression with sense of competence as the outcome, the predictor variables explained approximately $59 \%$ of the variance $[F(7,92)=21.57, \mathrm{p}<.001]$. The significant interaction term suggested that avoidant coping moderated the PSI scale of isolation (see Figure 2).

When depression was the outcome variable, the percentage of variance explained was $61 \%[F(8,92)=20.55, \mathrm{p}<.001]$. In this case, the social support provided by family moderated the PSI acceptability scale (see Figure 3).

In the final hierarchical regression with GHQ as the outcome, the predictor variables explained $60 \%$ of the variance $[\mathrm{F}(9,91)=17.70, \mathrm{p}<.001]$. Here, avoidant coping strategy was seen to moderate the PSI isolation scale (see Figure 4).

The significant predictors specific to each outcome measure can be seen in the regression models provided in Table 4.

\section{Discussion}

\section{Stress and ART}

This study shows that parents of newly born twins are at risk of general mental distress, but not at risk of more serious outcomes such as depression, as a result of their parenting role.

Previous research found that IVF mothers of multiples were more likely to score in the severe stress range than mothers of IVF and naturally conceived singletons $[16,23,24]$. 
While this is an interesting result it is important to note that no comparison is made with mothers of naturally conceived multiples. Three previous studies have compared IVF parents of twins with non-IVF parents of twins [25,26,39]. Cook et al. [25] and Gibson et al. [39] found that IVF parents reported greater parenting stress compared to non-IVF parents. However, both studies were based on small samples (26 and 27 parents respectively) and so it is difficult to generalise from the results found. In contrast Colpin et al. [26] did not find greater parenting stress for parents of 1year old IVF twins compared to non-IVF twins.

The current study extends the previous studies in examining stress and coping in parents of twins. The present study indicates that there are other factors and moderators that might be more important determinants of a parent's psychological distress than whether or not their twins were conceived naturally or via ART.

\section{Moderators of Stress}

Regression analysis indicates that approach coping is a significant positive predictor of all 3 outcomes. This suggests that approach coping is a maladaptive coping strategy in this context. Approach coping requires effort and it is, perhaps, this additional effort of attempting to cope with their present difficulties that adds to the psychological burden of parents. However, the lack of significant findings for the avoidant coping factor indicates that there is no evidence to suggest that avoiding the stressors is a helpful strategy either. The interaction terms are useful in shedding some additional light here. The relationship between the PSI isolation scale and the outcomes of sense of competence and GHQ is moderated by avoidant coping. The interaction plots indicate that in these cases the optimum situation (in terms of better outcomes) is a combination of high avoidant coping and low isolation. In other words, parents benefit from engaging in an avoidant coping style when they are satisfied with the availability of social interaction. Yet, an avoidant coping style is particularly damaging to the outcomes if the parents also experience low levels of social interaction. Indeed, the 
interaction term found for the depression scale follows the same pattern. In this case the perceived support provided by family members moderates the relationship between the PSI acceptability scale and depression. The interaction plot suggests that depression is likely to be lowest among parents who feel that their children meet their expectations and who also feel that they have high levels of social support from members of their family. The role of the spouse (the emotional and active support provided by the spouse) is also a significant predictor of depression and the perceived social support provided by friends is a significant predictor of sense of competence. Overall, therefore, the results suggest that social interaction and support is an important variable in terms of the psychological outcomes experienced by parents of twins.

Type of Support

The importance of the appropriate type of social support being available to parents as they need it is consistent with previous evidence [40], indicating that social support is not the answer to the problems of parenting stress, but the individualised application of social support will be hugely beneficial to parents. The present study highlights the complexity of the introduction of social support by demonstrating that its mode of action is mostly via an interaction term. Indeed, Quittner and colleagues [41] also indicate the complexity of the relationship between social support and parenting stress, although they question whether a moderating or mediating model is most appropriate.

For parents managing twins it might be obvious that some instrumental support would be useful. However, the parents in this study also pointed towards the value of social interaction, which suggests a more emotional or informal type of support.

\section{Child Factors}

The PSI mood scale is a significant predictor of 2 outcomes (sense of competence and depression). This indicates that the parent's perception of the child's mood has an important 
impact on the psychological outcomes of the parent. High scores on the PSI mood scale are associated with children who show dysfunction in their affective functioning, for example, cry frequently or do not display signs of happiness. High scores on this scale are linked to impairment in the PSI attachment scale. An association between these scales was found with PSI competence scores as the outcome measure. Scores on the PSI attachment scale are associated with two possible sources of dysfunction: firstly that the parent doesn't feel a sense of emotional closeness to the child or secondly the parent has a real or perceived inability to observe and understand the child's feelings and/or needs accurately [42].

The findings from the present study support the hypotheses of Cutrona and Troutman [43] who suggested that infant temperament and social support are important predictors of maternal postpartum depression.

\section{Limitations}

The present study had a number of strengths; however it was not without its limitations. One limitation was not collecting data regarding participants’ socio economic status. Additionally, there might be a response bias from the participants who responded to the request to complete the questionnaires. The population data available suggests that no bias existed in terms of maternal age, but there is no other information available for parents of twins in the region that allows a comparison with our sample. Therefore, the possibility remains that parents with poorer functioning may have been less likely to participate in the study. Similarly ART parents may have been more likely to participate as they have already invested much time and energy into becoming parents. Furthermore, the data analysis strategy was exploratory and therefore the findings presented here are suggestions that might form the basis of useful models or hypotheses that will require further confirmatory analysis. Conclusions 
In the transactional model of stress (TMS) [22] the cognitive appraisal of stressors and availability of personal support resources and coping strategies act as moderators of stress responses. The findings of the current study add support to the TMS model of parental stress.

The current study indicates that factors such as social interaction and support, the child's temperament and the parent's coping strategy (but not whether the twins were conceived via ART or not) are important determinants of the psychological distress of parents of newly born twins. Parents of twins, therefore, are a group for whom specific interventions ought to be developed with the aim of minimising distress. Practitioners may be reluctant to highlight the medical and social disadvantages of higher-order births [44]. Increasing awareness that the combination of a multiple birth and a difficult child increases the mother's emotional vulnerability [9] may help to build awareness among the front line professionals with whom parents of newborns may have most contact.

Interventions could include ante and post- natal counselling. Honey and colleagues have suggested the use of coping effectiveness training (CET) [45], which draws on appraisal and coping theory. However, there is clearly a role for groups such as the Twins and Multiple Births association in providing that crucial social interaction and support that seems to be important in maintaining the emotional well-being of parents of twins. 
Acknowledgements

The authors would like to thank Dr Ann Hamilton, Dr Robin Ashe, Dr Noel Heasley, Dr Michael Parker, Sharon Davidson (Infertility Network UK) and the staff involved in the Northern Ireland Maternity Services Information System (NIMATS) for their help with data collection.

Declaration of Interest

The authors have no competing interests to report. 


\section{References}

[1] Webster-Stratton C. The relationship of marital support, conflict, and divorce to parent perceptions, behaviours, and childhood conduct problems. J Marriage Fam 1989;51:417-30.

[2] Milgrom J, McCloud PI. Parenting Stress and Postnatal Depression. Stress Med 1996;12:177-86.

[3] Pesonen AK, Raikkonen K, Heinonen K, Komsi N, Jarvenpaa AL, Strandberg T. A transactional model of temperamental development: evidence of a relationship between child development and maternal stress over five years. Soc Dev 2008;17:326-40.

[4] Abidin RR., Jenkins CL, McGaughey MC. The relationship of early family variables to children’s subsequent behavioural adjustment. J Child Clin Psychol 1992;21:60-9.

[5] Abidin RR. Parenting Stress Index. $3^{\text {rd }}$ ed. Odessa, FL: Psychological Assessment Resources; 1995.

[6] Pinborg A, Loft A, Andersen AN. Neonatal outcome in a Danish national cohort of 8602 children born after in vitro fertilisation or intracytoplasmic sperm injection: the role of twin pregnancy. Obstet Gynaecol Scand 2004;83:1071-8.

[7] Olivennes F, Golombok S, Ramogida C, Rust J. Behavioral and cognitive development as well as family functioning of twins conceived by assisted reproduction: findings from a large population study. Fertil Steril 2005;84:725-33.

[8] Fisher J, Stocky A. Maternal perinatal mental health and multiple births: implications for practice. Twin Res 2003;6:506-513.

[9] Sheard C, Cox S, Oates M, Ndukwe G, Glazebrook C. Impact of a multiple, IVF birth on post-partum mental health: a composite analysis. Hum Reprod 2007;22:2058-65.

[10] Segal NL. Entwined Lives: Twins and What They Tell us About Human Behaviour. New York: Dutton; 1999. 
[11] Bryan EM. Loss in higher multiple pregnancy and multifetal pregnancy reduction. Twin Res Hum Genet 2002;5:169 -74.

[12] Lytton H. Parent child interaction: the socialization process observed in twin and singleton families. New York: Plenum; 1989.

[13] Rutter M, Thorpe K, Greenwood R, Northstone K, Golding J. Twins as a natural experiment to study the causes of mild language delay. I. Design: twin-singleton differences in language, and obstetric risks. J Child Psychol Psychiatr 2003;44:326-41.

[14] Lytton H, Gallagher L. Parenting twins and the genetics of parenting. In: Bornstein MH, Ed. Handbook of Parenting. Vol 1. NJ: Lawrence Erlbaum Associates; 2002, 227-53. [15] Scottish Intercollegiate Guidelines Network. Postnatal Depression and Puerperal Psychosis A National Clinical Guideline. Edinburgh: SIGN Executive; 2002.

[16] Glazebrook C, Sheard C, Cox S, Oates M, Ndukwe G. Parenting stress in first time mothers of twins and triplets conceived after in vitro fertilization. Fertil Steril 2004;81:50511.

[17] Hammarberg K, Fisher JRW, Wynter KH. Psychological and social aspects of pregnancy, childbirth and early parenting after assisted conception: a systematic review. Hum Reprod Update 2008;14:395-414.

[18] Dickey RP. The relative contribution of assisted reproductive technologies and ovulation induction to multiple births in the United States 5 years after Society for Assisted Reproductive Technology/ American Society for Reproductive Medicine recommendations to limit the number of embryos transferred. Fertil Steril 2007;88:1554-61.

[19] Human Fertilisation and Embryology Authority (HFEA). Fertility Problems and Treatment- Facts and Figures. http://www.hfea.gov.uk/PressOffice//Factsandfigures (accessed August $5^{\text {th }}$ 2010). 
[20] Verhaak CM, Smeenk JM, van Minnen A, Kremer JA, Kraaimaat FW. A longitudinal, prospective study on emotional adjustment before, during and after consecutive fertility treatment cycles. Hum Reprod 2005;20:2253-60.

[21] Goldfarb J, Kinzer DJ, Boyle M, Kurit D. Attitudes of in vitro fertilization and intrauterine insemination couples toward multiple gestation pregnancy and multifetal pregnancy reduction. Fertil Steril 1996;65:815-20.

[22] Lazarus RS, Folkman S. Stress, Appraisal and Coping. New York: Springer; 1984.

[23] Baor L, Soskolne V. Mothers of IVF and spontaneously conceived twins: a comparison of prenatal maternal expectations, coping resources and maternal stress. Hum Reprod 2010;25:1490-6.

[24] Honey K, Morgan M, Bennett P. A stress-coping transactional model of low mood following childbirth. J Reprod Infant Psychol 2003;21:129-43.

[25] Cook R, Bradley S, Golombok S. A preliminary study of parental stress and child behaviour in families with twins conceived by in-vitro fertilisation. Hum Reprod 1998;13:3244-6.

[26] Colpin H, De Munter A, Nys K, Vandemeulebroecke L. Parenting stress and psychosocial well-being among parents with twins conceived naturally or with reproductive technology. Hum Reprod 1999;14:3133-7.

[27] Abidin RR. Parenting Stress Index-Manual. Charlottesville, VA: Paediatric Psychology Press; 1983.

[28] Stein REK, Reissman EK. The development of an Impact on Family Scale: preliminary findings. Med Care 1980;18:465-72.

[29] McLinden-Mott SE, Braeger T. The Impact on Family Scale: An adaptation for families of children with handicaps. J Early Intervention; 1988;12:217-23. 
[30] Carver CS. You want to measure coping but your protocol's too long: Consider the Brief COPE. Int J Behav Med 1997;4:92-100.

[31] Carver CS, Scheifer MF, Weintraub JK. Assessing coping strategies: a theoretically based approach. J Pers Soc Psychol 1989;56:267-83.

[32] Zimet GD, Dahlem NW, Zimet SG, Farley GK. The Multidimensional Scale of Perceived Social Support. J Pers Assess 1988;52:30-41.

[33] Zimet GD, Powell SS, Farley GK, Werkman S, Berkoff KA. Psychometric characteristics of the Multidimensional Scale of Perceived Social Support. J Pers Assess 1990;55:610-17.

[34] Goldberg DP, Williams P. A User's Guide to the General Health Questionnaire. Windsor: NFER-Nelson; 1988.

[35] Goldberg DP, Gater R, Sartorious N, Ustun TB, Piccenelli M, Gureje O, et al. The validity of two versions of the GHQ in the WHO study of mental illness in general health care. Psychol Med 1997;27:191-7.

[36] Vilska S, Unkila-Kallio L, Punamaki RL, Poikkeus P, Repokari L, Sinkkonen J, et al. Mental health of mothers and fathers of twins conceived via assisted reproduction treatment: a 1-year prospective study. Hum Reprod 2009;24:367-77.

[37] Johnston M, Wright SC, Weinman J. Measures in Health Psychology: a User's Portfolio. NFER-Nelson; 1995.

[38] Northern Ireland Statistics and Research Agency (NISRA). Registrar General Annual Reposrt. http://www.nisra.gov.uk/demography/default.asp98.htm (accessed July 7th 2015). [39] Gibson FL, Ungerer JA, Leslie GI. Maternal attitudes to parenting and observations of the mother-child relationship and interaction with IVF twins. Paper presented at the $11^{\text {th }}$ World Congress on In Vitro Fertilisation and Human Reproduction Genetics, Sydney (Australia), May 1999. 
[40] Thoits PA. Stress, coping, and social support processes: Where are we? What next? J Health Soc Behav 1995;53-79.

[41] Quittner AL, Glueckauf RL, Jackson DN. Chronic parenting stress: moderating versus mediating effects of social support. J Pers Soc Psychol 1990;59:1266-78.

[42] Moran G, Pederson D, Pettit P, Krupka A. Maternal sensitivity and infant-mother attachment in a developmentally delayed sample. Infant Behav Dev 1992;15:427-42.

[43] Cutrona CE, Troutman BR. Social support, infant temperament, and parenting selfefficacy: a mediational model of postpartum depression. Child Dev 1986;57;1507-18. [44] Jones HW. Multiple births: how are we doing? Fertil Steril 2003;79:17-21. [45] Chesney MA, Folkman S. Psychological impact of HIV disease and implications for intervention. Psychiatr Clin North Am 1994;17:163-82. 
Table 1: Component loadings for Brief COPE

\begin{tabular}{lll}
\hline & Approach & Avoidant \\
\hline Planning & .814 & \\
Positive Reframing & .803 & \\
Acceptance & .795 & \\
Instrumental Support & .785 & \\
Active Coping & .746 & \\
Venting & .663 & \\
Emotional Support & .662 & \\
Humor & .651 & \\
Self-Blame & .627 & \\
Self Distraction & .502 & .395 \\
Substance Use & & .782 \\
Denial & & .449 \\
Behavioural & & .615 \\
Disengagement & & \\
Religion & & \\
\hline
\end{tabular}

All component loadings less than an absolute value of 0.3 have been suppressed 
Table 2: Sample Demographics

\begin{tabular}{|c|c|c|}
\hline & & $\%$ \\
\hline \multirow[t]{7}{*}{ Age (years) } & Under 21 & 1.9 \\
\hline & $21-25$ & 7.7 \\
\hline & $26-30$ & 17.3 \\
\hline & $31-35$ & 31.7 \\
\hline & $36-40$ & 31.7 \\
\hline & $41-50$ & 8.7 \\
\hline & $50+$ & 1.0 \\
\hline \multirow[t]{3}{*}{ Employed } & Employed & 56.7 \\
\hline & Not employed & 15.4 \\
\hline & Maternity leave & 27.9 \\
\hline \multirow[t]{2}{*}{ Employment } & Full Time & 66.1 \\
\hline & Part Time & 33.9 \\
\hline \multirow[t]{5}{*}{ Education } & GCSE/O Levels & 23.9 \\
\hline & AS/A Levels & 20.2 \\
\hline & Further Education & 25.9 \\
\hline & University Degree & 5.3 \\
\hline & Post-grad & 24.8 \\
\hline \multirow{3}{*}{$\begin{array}{l}\text { Time off after birth of twins } \\
\text { (months) }\end{array}$} & Mean & 6.08 \\
\hline & SD & 6.29 \\
\hline & Range & $0-36$ \\
\hline \multirow[t]{3}{*}{ Length of Relationship (years) } & Mean & 8.94 \\
\hline & SD & 4.66 \\
\hline & Range & $1-19$ \\
\hline \multirow[t]{2}{*}{ Infertility Treatment } & Yes & 58.7 \\
\hline & No & 41.3 \\
\hline
\end{tabular}


Table 3: Descriptive Statistics for Self-Report Measures

\begin{tabular}{llll}
\hline & Subscale & Mean & SD \\
\hline PSI Child Factors & Distractibility/ Hyperactivity & 24.31 & 4.55 \\
\cline { 2 - 4 } & Adaptability & 24.72 & 5.84 \\
\cline { 2 - 4 } & Reinforces Parent & 8.89 & 2.88 \\
\cline { 2 - 4 } & Demandingness & 16.86 & 4.80 \\
\cline { 2 - 4 } & Mood & 9.05 & 3.06 \\
\cline { 2 - 4 } & Acceptability & 11.31 & 3.72 \\
\hline PSI Parent Factors & Competence & 27.76 & 6.74 \\
\cline { 2 - 4 } & Isolation & 14.31 & 4.17 \\
\cline { 2 - 4 } & Attachment & 11.81 & 3.30 \\
\cline { 2 - 4 } & Health & 13.44 & 4.12 \\
\cline { 2 - 4 } & Role Restriction & 20.58 & 5.49 \\
\cline { 2 - 4 } & Depression & 19.13 & 6.58 \\
\cline { 2 - 4 } & Spouse & 18.81 & 5.80 \\
\hline GHQ & Total Score & 11.95 & 4.82 \\
\hline Impact on the Family & Financial Burden & 9.46 & 2.20 \\
\hline MPSS & Friends & 5.07 & 1.49 \\
\cline { 2 - 4 } & Family & 5.56 & 1.53 \\
\cline { 2 - 4 } & Significant Other & 0.00 & 1.44 \\
\cline { 2 - 4 } & Global Support & 1.23 \\
\hline COPE Subscales & Approach coping & 1.00 \\
\cline { 2 - 4 } & Avoidant coping & & \\
\hline
\end{tabular}


Table 4: Summary of Separate Regression Analyses for each Outcome

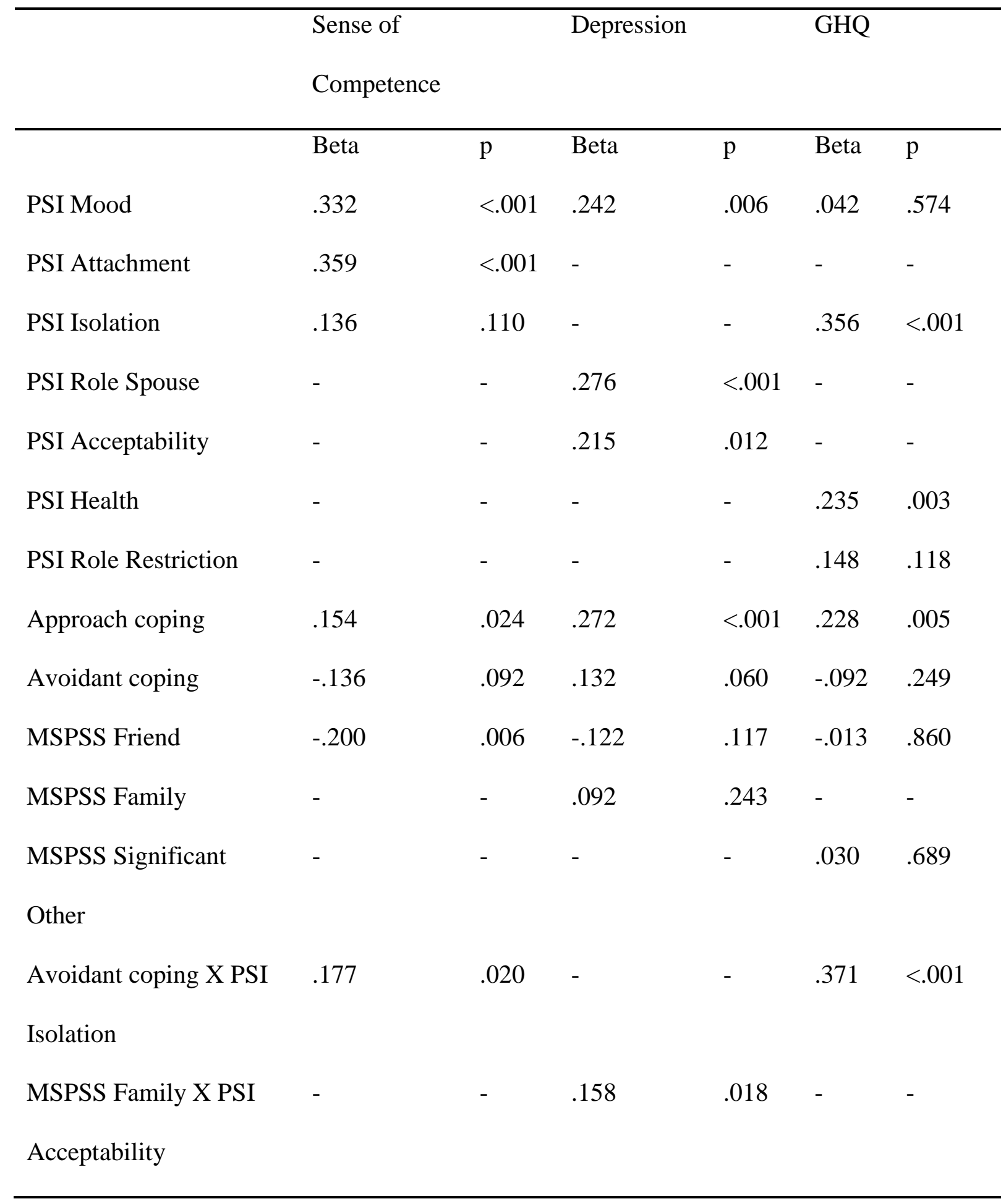


$\underline{\text { Potential Stressors }}$

Conception by ART or not

Financial burden

Child Distractibility/Hyperactivity

Child Adaptability

Child Reinforces Parent

Child Demandingness

Child Mood

Child Acceptability

Parent Isolation

Parent Attachment

Parent Health

Parent Role Restriction

Role of Spouse

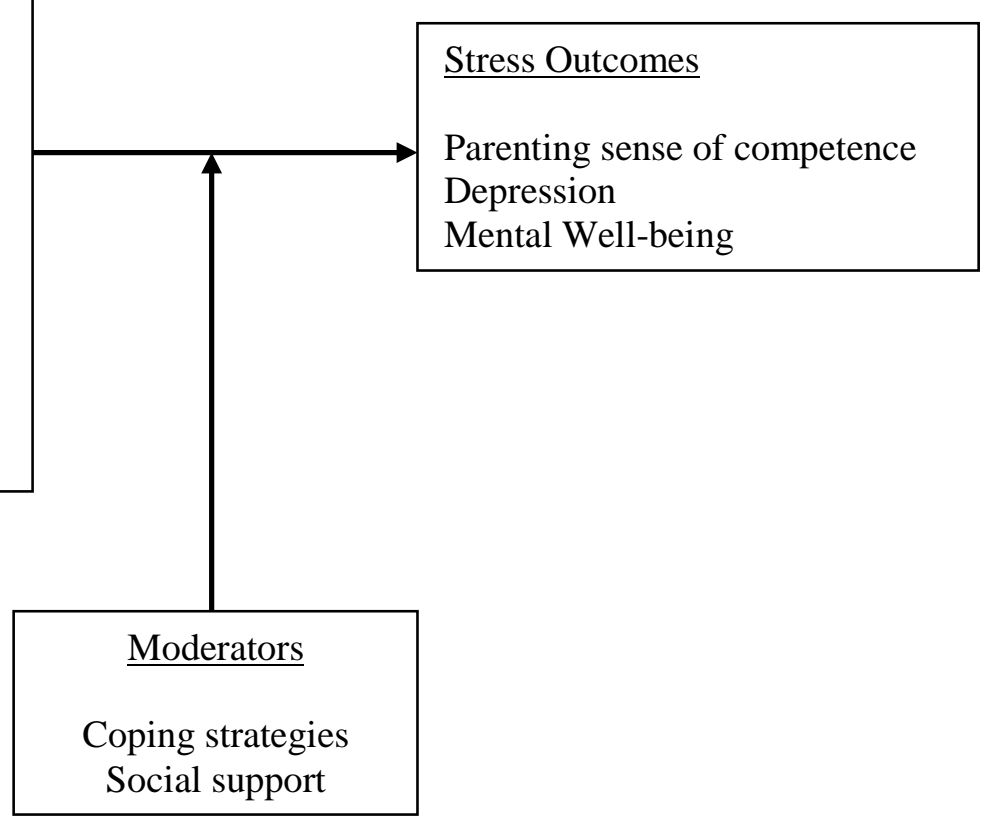

Figure 1: Operationalisation of the Transactional Model of Stress in the Current Study 


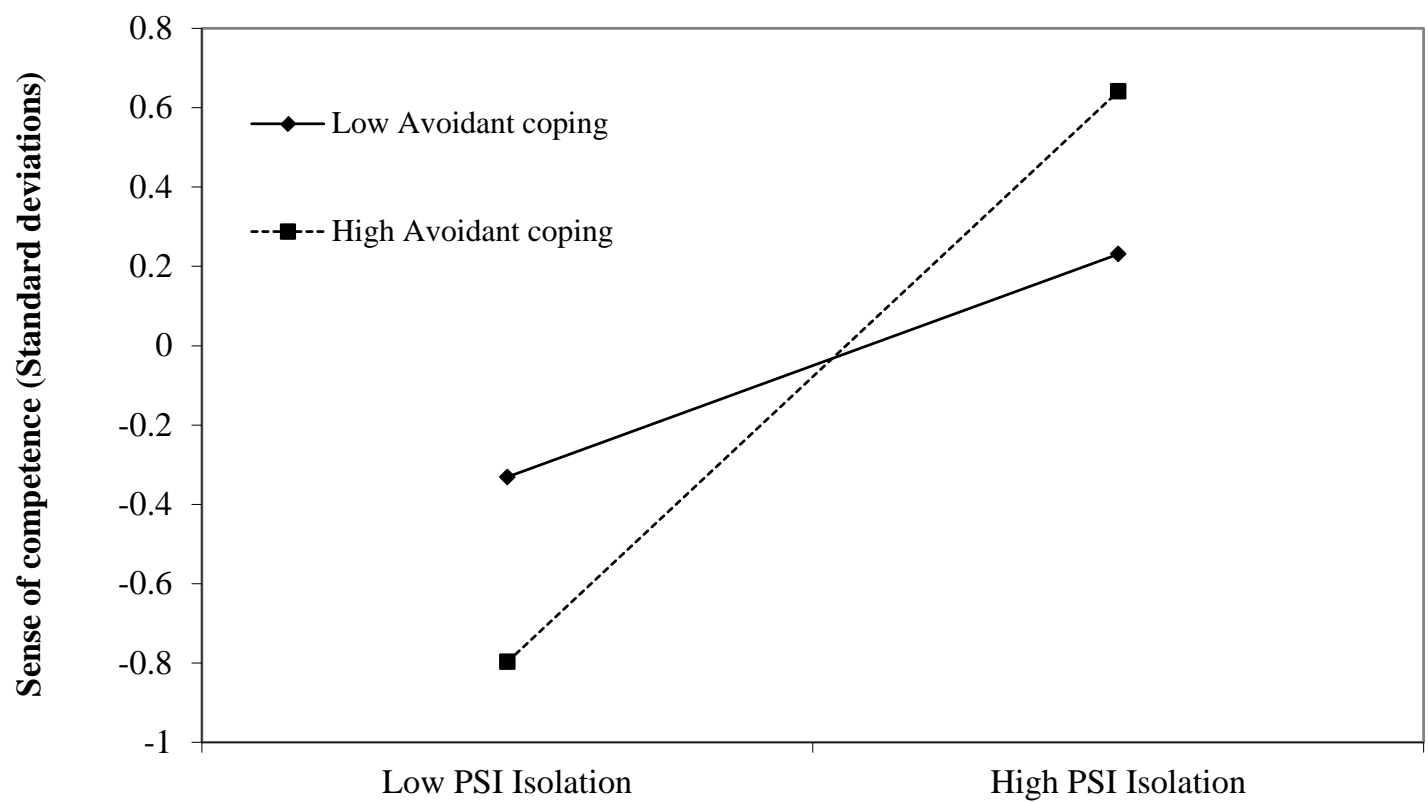

Figure 2: Interaction plot for avoidant coping and isolation with sense of competence 


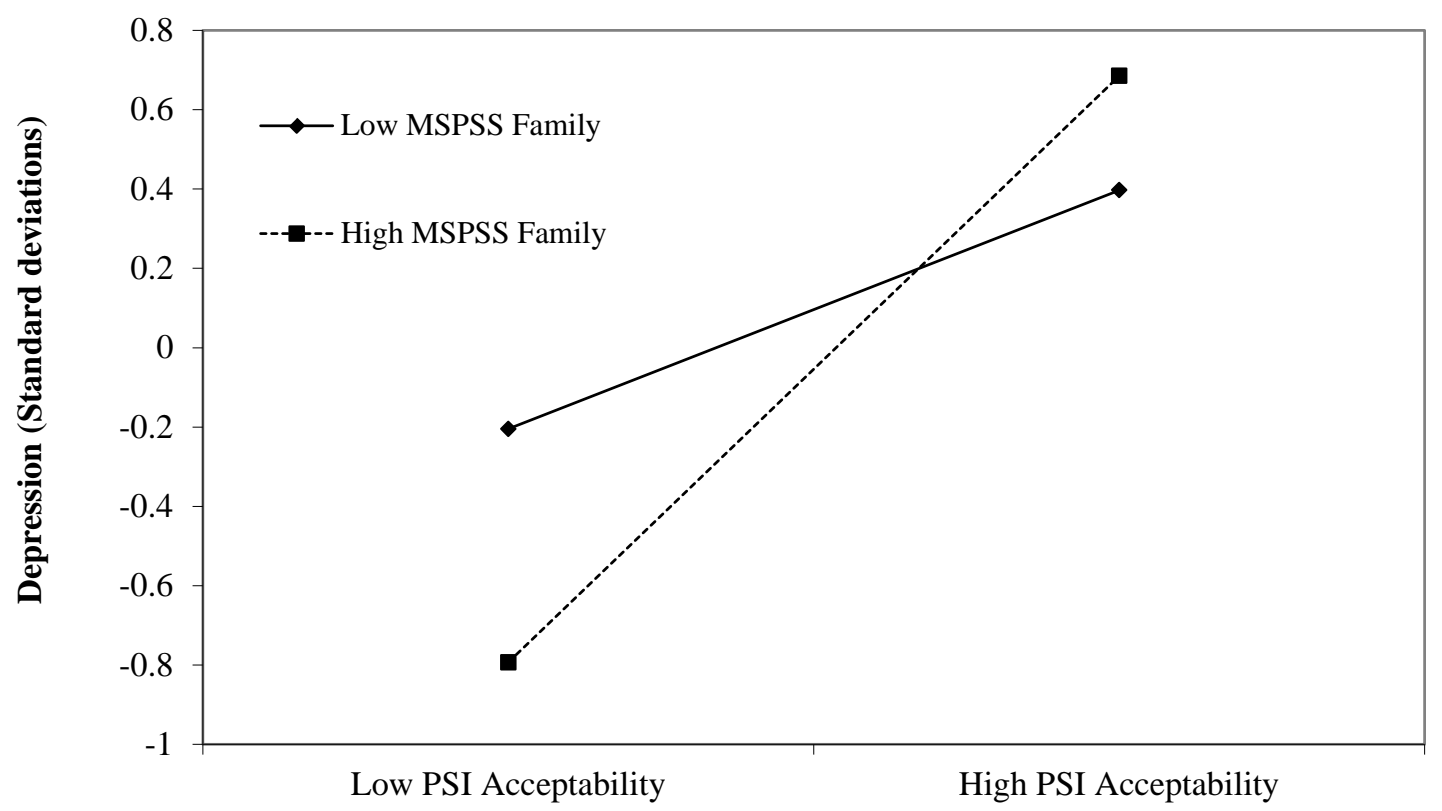

Figure 3: Interaction plot for family support and acceptability with depression 


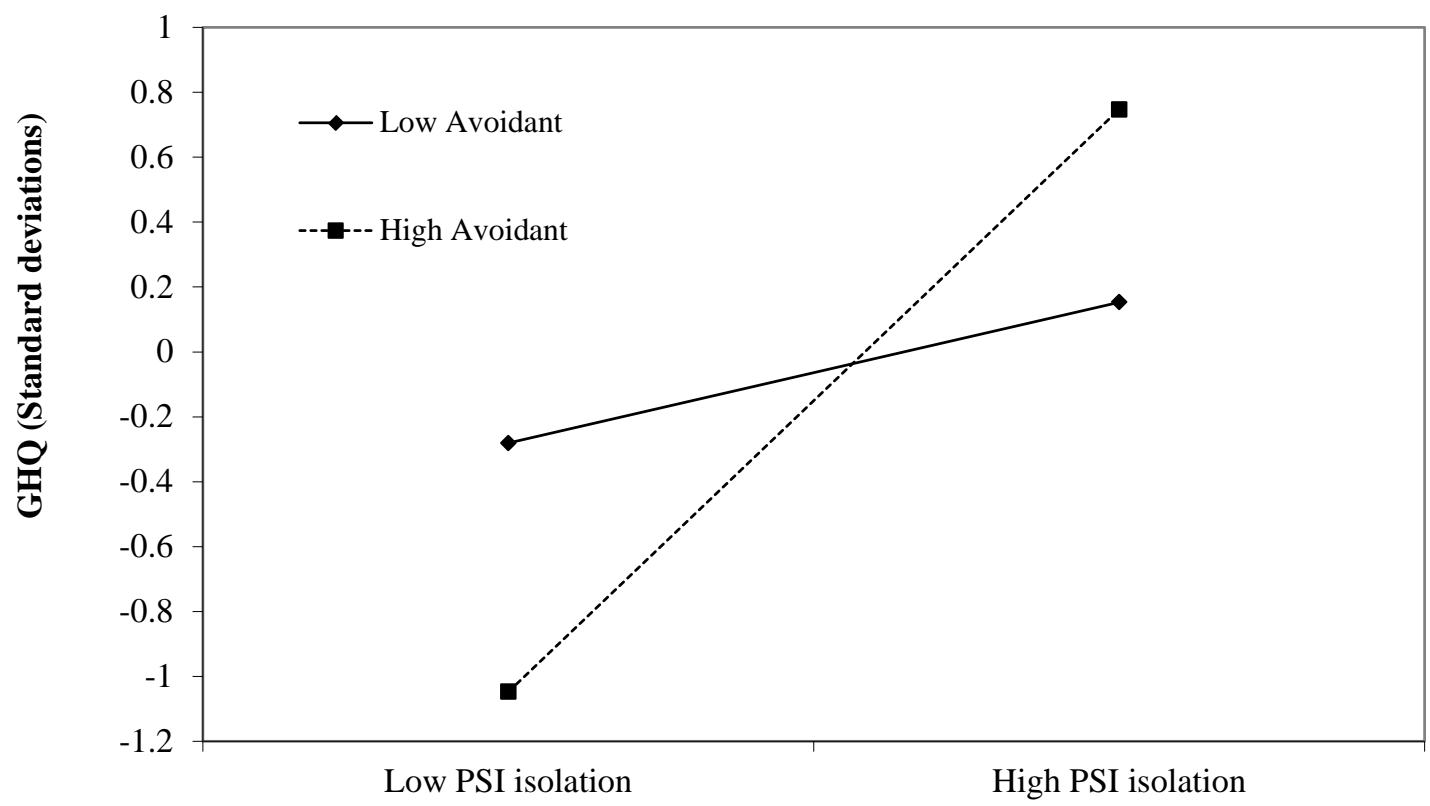

Figure 4: Interaction plot for avoidant coping and isolation with GHQ 